\title{
CONTRIBUIÇÕES E LIMITAÇÕES DO SISTEMA DE ORGANIZAÇÃO MODULAR DE ENSINO (SOME) NA FORMAÇÃO EDUCACIONAL DE JOVENS NA COMUNIDADE DE JOROCA GRANDE NO MUNICÍPIO DE CAMETÁ/PARÁ.
}

\author{
Kátia Cristina Pereira Cabral ${ }^{1}$ \\ Nidilene do Socorro Rodrigues Braga² \\ Rosimara do Socorro Barra Duarte ${ }^{3}$
}

\section{RESUMO}

Este artigo busca analisar o Sistema de Organização Modular de Ensino (SOME), como uma política pública educacional focalizada que envolve, em sua teoria, os paradigmas do Federalismo Cooperativo. Analisa-se como esta política educacional tem sido implementada no município de Cametá/PA para formação de jovens do campo, tendo como pano de fundo o Regime de Colaboração entre os entes federados. Trata-se de um estudo de natureza qualitativa com enfoque na análise de conteúdo, subsidiada nas diretrizes e nos princípios do SOME. Dentre os principais autores da pesquisa, destacam-se Corrêa e Barreto (2009), Cury (2009), Kuenzer (2009), Castro (2005), entre outros como Frigotto e Ciavatta (2011) e Melo e Duarte (2011). Dentre as técnicas de pesquisa, destaca-se análise documental e entrevistas semiestruturadas com um total de 4 (quatro) sujeitos, que estão ligados diretamente ao sistema. Concluiu-se que é de suma importância implantar políticas educacionais voltadas, principalmente, para a juventude, pois ela constitui uma classe social cujos direitos têm sido historicamente negados.

Palavras-chave: SOME. Políticas Educacionais. Regime de colaboração.

\section{INTRODUÇÃO}

O presente artigo têm como objetivo investigar as contribuições e limitações do Sistema de Organização Modular de Ensino (SOME) na formação educacional de jovens, como uma política educacional que envolve em sua teoria, uma política para

\footnotetext{
${ }^{1}$ Mestranda em ciências e educação pela Facultad Interamericana de Ciências Sociales. E-mail: katiacabral1503@gmail.com

${ }^{2}$ Mestranda em ciências e educação pela Facultad Interamericana de Ciências Sociales. E-mail: nidilenebraga@gmail.com

${ }^{3}$ Mestranda em ciências e educação pela Facultad Interamericana de Ciências Sociales. E-mail: rosi.barra2015@gmail.com
} 
o Ensino Médio do Campo, analisando como este sistema vem sendo implementado e efetivado no munícipio de Cametá, especificamente na comunidade de Joroca Grande para formação de jovens, no âmbito educacional, profissional e social.

A importância desta pesquisa se dá pela relevância educacional, social, política e profissional que o SOME ocupa no cenário estadual, e trazendo para o local é essencial discutir educação, através de políticas ou programas educacionais que venham a atender a clientela jovem do município como Cametá, haja vista que, este município apresenta baixos índices educacionais na educação do campo e um Sistema Educacional como o SOME tem potencial para promover avanços no processo de ensino aprendizagem deste município.

Para justificar o presente diálogo, buscamos na literatura a compreensão de como se configura o processo de contribuições e limitações desse sistema considerando sua efetivação, que por sua vez, guarda contradições na política educacional em consequente compreendemos o papel social da juventude a nível estadual e local, para além das questões de transição de uma fase de vida, mas como uma juventude ativa e pensante que busca melhorias na qualidade de vida e bemestar de sua coletividade.

Neste primeiro momento dialogamos com Corrêa e Barreto (2009), Cury (2009), Frigotto e Ciavatta (2011), Kuenzer (2009) entre outros autores, que discutem a Política Educacional para o Ensino Médio. Para o entendimento de juventude dialogamos com Castro (2005), Frigotto (2003) e Melo e Duarte (2011). Essas referências, além de possibilitar a compreensão do objeto, também fundamentam teoricamente a presente pesquisa.

Para dar direcionamento à pesquisa, elegemos as seguintes questões norteadoras: Como se deu a política de implementação e efetivação do Sistema de Organização Modular de Ensino no município de Cametá? Que contribuições são identificadas pelos alunos do Sistema de Organização Modular de Ensino para a melhoria da qualidade do ensino do meio rural da comunidade de Joroca Grande, município de Cametá? E como os alunos da comunidade de Joroca Grande, município de Cametá, estado do Pará, superam os desafios para a efetividade do processo educativo ofertado pelo SOME? 
Com base nessa problemática, propomo-nos em nossos objetivos específicos: Conhecer como se deu a política de implementação e efetivação do Sistema de Organização Modular de Ensino (SOME) no município de Cametá/Pá, identificar as contribuições apontadas pelos alunos do Sistema de Organização Modular de Ensino para a melhoria da qualidade do ensino do meio rural da comunidade de Joroca Grande, município de Cametá e analisar como os alunos da comunidade de Joroca Grande, município de Cametá, estado do Pará, superam os desafios para a efetividade do processo educativo ofertado pelo SOME. Para este estudo se materializar realizamos a análise em documentos oficiais e a fala dos entrevistados através de perguntas semiestruturadas.

Metodologicamente, o trabalho se caracterizou por ser uma pesquisa de campo do tipo qualitativa. A estratégia de investigação escolhida para o encaminhamento deste processo de pesquisa foi a pesquisa documental e o estudo de caso, por se tratar de uma realidade desvelada por meio de interpretação de um contexto com informações coletadas diante dos pontos de vistas dos pesquisados. Por meio desta técnica coletamos o máximo de dados possíveis no contexto da pesquisa. A técnica de observação frequentemente é combinada com a entrevista, isto é, conduzida no ambiente natural e de tom sistemático e às vezes informais. As entrevistas foram gravadas e tomamos notas para a apreciação posterior de nossas inferências. Nesse sentido a entrevista foi utilizada possibilitando o contato imediato com os segmentos da comunidade escolar nos locais de pesquisa, na fase da coleta de dados. As entrevistas foram semiestruturadas com poucas questões/guias, quase sempre abertas, aplicadas ao segmento pesquisado, ou seja, quatro alunos.

Após a coleta de dados, iniciou-se o processo de análise, classificação e interpretação das informações coletadas. Nesta pesquisa, após a coleta dos dados, realizamos uma interpretação das informações com o máximo de criticidade possível, sempre tomando por base o referencial teórico utilizado.

A pesquisa apresentou três momentos em seu desenvolvimento operacional, a saber: 1ํㅡ etapa: revisão bibliográfica e levantamento documental acerca da educação básica no Brasil e no estado do Pará. A 2ª etapa constituiu-se no momento da pesquisa de campo, em que realizamos preliminarmente visitas à comunidade de Joroca Grande, em Cametá, com o objetivo de estabelecer uma relação de apoio com 
os sujeitos locais para a efetivação da investigação, o que foi alcançado e a $3^{\text {a }}$ etapa constituiu-se na análise do material empírico, ou seja, na sistematização e organização de todas as informações recolhidas em campo e na interpretação do material recolhido (transcrição das entrevistas e observações, imagens, documentos, etc.).

\section{MÉTODOS}

Tipo de Abordagem: Esta pesquisa tem caráter qualitativo, onde elucidamos a escolha da pesquisa qualitativa considerando que a mesma procura quantificar opiniões na forma de observações, além de analisar as diferenças e singularidades das variáveis apontadas pela metodologia adotada.

Tipo de pesquisa: A análise consiste em uma pesquisa de campo, pois a mesma admite a relação direta entre o pesquisador e o sujeito pesquisado.

População: Os sujeitos da pesquisa são 4 alunos da referida comunidade envolvidos nessa modalidade de ensino.

Local: Para tanto o estudo será realizado na Escola Municipal de Ensino Fundamental Prof. a Raimunda Pontes, localizada no Rio Joroca Grande, município de Cametá/Pará.

Instrumentos de coleta de dados: Como instrumento de coleta de dados consideramos a entrevista estruturada com perguntas já previstas, cuja finalidade é tabular dados.

Análises dos dados: A análise de dados efetua-se a partir da análise do conteúdo que consiste em um conjunto de técnicas de análise de comunicações, que tem como objetivo ultrapassar as incertezas e enriquecer a leitura dos dados coletados.

\section{PROGRAMA IMPLANTADO PARA O ENSINO MÉDIO NO PARÁ 3.1 Sistema de Organização Modular de Ensino (SOME)}

O MEC, com o objetivo de garantir o acesso à educação de qualidade aos jovens do Ensino Médio, vem ampliando suas ações por meio de políticas e programas que atendam de maneira efetiva esse público. Para isso, tem desenvolvido ações conjuntas com Estados e o Distrito Federal de forma a criar condições necessárias 
para a melhoria da qualidade dessa etapa da Educação Básica (MINISTÉRIO DA EDUCAÇÃO, 2013).

No estado do Pará, o processo de expansão e universalização do Ensino Médio já vem acontecendo ao longo de 36 anos por meio do Sistema de Organização Modular de Ensino (SOME). Esse sistema foi criado para expandir as oportunidades educacionais em nível de ensino médio para a população do interior do estado do Pará, pois muitos municípios não possuem condições de promover este ensino em algumas localidades devido ao difícil acesso, ausência de recursos humanos habilitados e também pelas questões econômicas dos muitos municípios paraenses. Sua operacionalização está pautada na Resolução n 161/82 de 3/11/82. O SOME é uma proposta de ensino adequada à realidade das comunidades rurais - ribeirinhas, de planaltos e várzeas - e às grandes distâncias do extenso território do Pará. Um projeto que visa garantir a Educação Básica, especialmente em ensino de nível médio, às populações de comunidades rurais nas quais não existe rede regular de ensino.

Essa alternativa de educação formal, de caráter transitório, surge originalmente com os seguintes objetivos: expandir as oportunidades da Educação Básica; interiorizar a educação; fixar o homem na região em que vive; democratizar o ensino médio; oferecer ao homem do campo, condições de participação no processo de mudanças nas políticas sociais; melhorar o nível de vida e bem-estar social da comunidade e ampliar o mercado de trabalho para o profissional de educação (PARÁ, 2008).

O processo de expansão do ensino médio no estado do Pará vem ocorrendo a partir da década de 1980, que segundo Corrêa e Barreto (1999, p. 33):

\footnotetext{
Muito tenha sido realizado dentro de um clima democrático, foi insuficiente no que concerne a democratização de oportunidades de acesso aos estabelecimentos de ensino, particularmente a modalidade média, a qual continuou segregando do acesso ao saber um número significativo da população escolarizável.
}

Para o autor esse sistema de ensino ainda não garante escolarização para muitos jovens e adultos do estado paraense, pois não podemos deixar de considerar que são inúmeras as dificuldades de interiorização do estado amazônico entrecortado por rios, lagos e igarapés e uma população pulverizada em pequenas localidades isoladas dos centros urbanos, bem como a ausência de profissionais habilitados, 
especialmente nas disciplinas de física, química, matemática, biologia, filosofia e sociologia para atuarem no ensino médio. Porém, percebe-se que, na maioria das leituras vigentes relacionadas ao atual ensino médio, sua progressão é visível, pois hoje já está garantido por lei o acesso a essa etapa de ensino e um considerável aumento do número de matrículas no sistema público educacional. Entretanto, um grande problema, relacionado à qualidade desse ensino, ainda precisa ser resolvido, pois ainda há baixos níveis de aproveitamento e de desempenho dos estudantes, ao lado de altos índices de repetência e de evasão.

Apesar do estado do Pará ter assumido o desafio de construir coletivamente uma Educação de Qualidade, a fim de elaborar um instrumento para nortear a reorganização da educação básica - favorecendo práticas formativas, orientadas por princípios democráticos e com diretrizes comuns - e a SEDUC ter assumido como tarefas prioritárias a qualidade de ensino, assim como melhorias na sua infraestrutura e qualificação docente, segundo o Caderno de elementos para uma política educacional democrática e de qualidade para todos (PARÁ, 2008a), percebe-se que há uma grande desconexão entre o que a lei vigente vem orientando e a prática vivenciada, em especial nas escolas de ensino médio.

O Sistema de Organização Modular de Ensino (SOME) surgiu no ano de 1982 sob a Coordenação da Fundação de Educação do Pará (FEP) com o objetivo de garantir acesso à escolarização de alunos, com 40h integrais definidas para o interior do estado, em especial àqueles que vivem em áreas de campos, rios e florestas, garantindo a continuação e/ou conclusão da educação básica. Esse sistema de ensino veio proporcionar oportunidade de escolarização a alunos de comunidades onde não há o ensino regular, pois por meio da parceria entre SEDUC/PA e Prefeituras municipais é possível que este nível de ensino seja ofertado, uma vez que há grandes dificuldades para que este aluno chegue à cidade devido à distância territorial e geográfica, além de número insuficiente de alunos para que se criem escolas regulares para esse nível de ensino em tais localidades.

Nos registros da SEDUC/PA, observa-se que o SOME inicialmente foi organizado para a formação de magistério, buscando dar formação para professores lecionarem nas séries iniciais do ensino fundamental, sob a Lei n 5.692/71 que traz as normas e regulamenta o SOME (BRASIL, 1971). Posteriormente, com a expansão 
desse sistema de ensino e com uma demanda crescente por parte do interior do estado também foram ofertados cursos de Administração, Contabilidade, Ciências Humanas e Biológicas (SEDUC, 2008).

Esse sistema de ensino foi regularizado pela Lei no 7.806 de 29 de abril de 2014, como uma política pública de educação do estado do Pará. Tendo como principais objetivos e fins assegurar ao aluno do interior o aceso à escola pública, gratuita e de qualidade e, principalmente, garantir os laços de convívio familiar de jovens e adultos que participam desse ensino, possibilitando a conclusão de seus estudos no Ensino Médio (PARÁ, 2014a).

Para que os municípios do estado do Pará implantem esse sistema de ensino é necessário que uma parceria seja firmada entre a SEDUC e o município e que haja o cumprimento de algumas condições, tais como: nesta comunidade não deve haver a existência de uma escola de esfera estadual que oferte o Ensino Médio; a localidade necessita ter escola pública municipal de ensino fundamental e que disponha de um espaço físico adequado para o funcionamento das aulas. E principalmente deve haver uma demanda considerável de alunos matriculados nessa comunidade. Assim como condições de permanência do professor, condições para um bom desenvolvimento do processo de ensino-aprendizagem e transporte de qualidade para os alunos.

Esse sistema de ensino funciona com duzentos dias letivos, divididos em cinco módulos com cada um, contendo quarenta dias. Para cada disciplina ofertada são necessárias pelo menos duas avaliações. Toda documentação é expedida pela escola-sede do município.

Para melhor compreensão, o SOME possui uma estrutura e funcionamento específicos e que vale compreendermos as terminalidades utilizadas nesse sistema de ensino:

a) Módulo: É constituído por um conjunto de disciplinas afins, ministradas e organizado de forma intensa e rotativa, desenvolvido num período de quarenta dias de aula e/ou atividades de ensino;

b) Etapa: É um conjunto de quatro módulos trabalhados num período letivo, correspondente à grade curricular de cada série/ano do ensino médio; 
c) Rodízio: É o período no qual cada grupo de disciplinas afins permanece na comunidade, desenvolvendo os conteúdos e atividades correspondentes à carga horária anual de cada disciplina;

d) Circuito: É o conjunto de quatro municípios onde um grupo de trabalho ou equipe desenvolve as suas atividades.

A lotação dos professores do quadro docente do SOME por circuitos e módulos devem ser de uma jornada de 40h integrais definidas no inciso III do artigo 35 da recente lei do SOME e fica sob a responsabilidade da Coordenação Geral do SOME/SEDUC/PARÁ (PARÁ, 2014). Quando o professor não consegue completar às 40h propostas por lei, deverá realizar Projetos Educacionais Específicos de sua área de atuação para poder atingir a jornada. Nem sempre o professor lotado no SOME é concursado para esse sistema, na maioria são lotações por apadrinhamento, respeitando apenas a disciplina que vai lecionar na qual deve possuir formação superior.

A remuneração dos Professores do SOME é um dos grandes atrativos por parte dos docentes lotados na SEDUC/PA, pois são lotados com 200h para trabalhar somente 100h, sendo este de jornada exclusiva para as atividades do SOME. A locação dos professores lotados no SOME é de inteira responsabilidade da parceria entre a SEDUC/PA e o município, cabendo ao município fazer o pagamento de um aluguel destinado à moradia dos professores. Vale ressaltar que aos alunos do SOME são garantidos, por lei, transporte escolar, merenda e livros didáticos. A rede municipal tem uma parceria com a rede estadual referente ao transporte escolar.

\section{ANÁLISE E DISCUSSÃO DOS DADOS}

Para desenvolver esta pesquisa, no primeiro momento foi pensado em vários sujeitos ligados diretamente ao sistema. Entre eles ressaltamos a importância de entrevistar os alunos, pois precisamos compreender sua visão diante das contribuições e limitações do sistema modular de ensino.

Vale ressaltar, que os critérios definidos para a escolha dos participantes da pesquisa consideraram o fato de haver três turmas, sendo escolhido 4 alunos do $3^{\circ}$ ano, preferencialmente por estarem inseridos nesta modalidade de ensino desde o $1^{\circ}$ 
ano e terem uma compreensão mais efetiva do processo, são únicos, não tendo outros sujeitos a entrevistar. Compreendemos que os sujeitos que foram entrevistados deram base de sustentação suficiente para compreender as contribuições do SOME na localidade de Joroca Grande. Dessa forma, deliberamos a fala dos entrevistados da seguinte maneira:

Quadro 1: As contribuições do SOME para a qualidade da educação

\begin{tabular}{|c|c|}
\hline Questões de investigação & Sujeitos/falas \\
\hline $\begin{array}{l}\text { Contribuições do Sistema de } \\
\text { Organização Modular de Ensino }\end{array}$ & $\begin{array}{l}\text { Suj. A= [...] O ensino por meio do } \\
\text { SOME é uma oportunidade, sem o } \\
\text { módulo estava tudo parado, inclusive } \\
\text { o sonho de cursar uma Universidade. } \\
\text { Suj. B=[...] A gente sente que a gente } \\
\text { não está só estudando eles querem } \\
\text { que a gente chegue nas } \\
\text { universidades, eles indicam livros para } \\
\text { pesquisar, sites apropriados para } \\
\text { pesquisa, promovem gincanas, } \\
\text { seminários e simulados com as } \\
\text { questões do ENEM. Agora tem } \\
\text { aqueles professores que levam a sério } \\
\text { mesmo e são flexíveis e que são a } \\
\text { maioria. } \\
\text { Suj. C= [...] o SOME contribui como } \\
\text { uma possibilidade de ingresso no } \\
\text { mercado de trabalho. } \\
\text { Suj. D= Para nós a vinda do SOME só } \\
\text { veio facilitar a nossa aprendizagem, } \\
\text { por que antes era muito difícil pra } \\
\text { gente ter que ir lá na cidade para } \\
\text { estudar era o local mais perto, ele veio } \\
\text { facilitar a nossa vida em termos de } \\
\text { Ensino. }\end{array}$ \\
\hline
\end{tabular}

\section{Fonte: Dados levantados pela pesquisa}

Podemos identificar claramente nos depoimentos dos estudantes descritos acima que a existência do SOME foi e continua sendo uma excelente alternativa de oportunidade de acesso à educação para aqueles que não podem se deslocar de seus lugares, ou seja, para os filhos de trabalhadores do campo. Considera-se o SOME um grande projeto de educação para o norte porque a Amazônia é extensa e a locomoção é difícil, assim se resolve dois grandes problemas o número de pessoas sem estudo e o inchaço populacional. 
Nas falas anteriores é possível verificar a forte ideia de que os alunos reconhecem o SOME como um meio de continuação de seus estudos e com o objetivo de concluir a educação básica, tendo a oportunidade de um trabalho e de poder participar do sistema de cotas para universidade pública. Há um reconhecimento, por parte dos alunos, que com o SOME eles podem continuar na comunidade estudando e ajudando no sustento familiar, contribuindo economicamente para a renda de sua própria família, reduzindo gastos, pois se necessitassem se deslocar para a região urbana o custo seria mais alto, custo este que infelizmente muitas famílias não podem arcar.

Considerando como fator positivo da implantação do SOME nesta localidade, volta-se ao favorecimento da permanência de jovens e adultos no seio familiar durante o período de escolarização. Entretanto, ao voltar os olhares para a qualidade desse ensino sabe-se que precisa ser enxergado pelas autoridades administrativas, que fazem parte desta parceria (SEDUC/PA e SEMED/CAMETÁ), com mais atenção, pois esses espaços ainda necessitam de mudanças estruturais significativas, tais como: boa iluminação, pintura, compra de carteiras, quadros, armários, material didático e de expediente, construção de novos espaços como biblioteca, sala de leitura, laboratório de informática e de ciências, assim como a construção de uma quadra polivalente coberta para a prática de esporte e lazer e convívio social (festas, gincanas, formatura e outros). Outro fator que merece destaque para a melhoria da escolarização desses alunos refere-se ao meio de transporte que não é suficiente para transportar todos os estudantes.

Percebe-se que os projetos que existem são mais locais e de iniciativa ora dos docentes ora dos discentes tornando a modalidade carente de mais políticas públicas. Contudo, os entrevistados argumentam que, sem o SOME ficaria muito difícil à vida desses no que diz respeito à escolarização, e veem na modalidade uma oportunidade de continuação dos estudos e ingresso no mercado de trabalho.

Assim, considerando a realidade sobre o papel do SOME na formação educacional fica evidente, por um lado, a insatisfação com uma formação deficitária, que não contemplou suas especificidades enquanto jovens do campo. A ausência de uma referência pedagógica que não fosse a figura do professor, está entre os fatores que contribuíram para a geração de um sentimento de não pertencimento e de 
insatisfação com o modelo somista. Por outro lado, talvez paradoxalmente, vem à tona um sentimento de contentamento por se ter entrado e concluído uma etapa escolar que, naquele lugar, é o máximo nível a que um morador pode chegar. Não obstante, não chega a ser um contentamento empolgado ou comemorado vibrantemente, pelo fato de essa formação não ter permitido ainda a inserção desses sujeitos em outros níveis de atuação no meio social.

No quadro 2 demonstra-se a metodologia e aprendizado a partir da visão dos alunos do SOME na pesquisa:

Quadro 2: Definição de temas e indicadores: SUJEITO A e D

\begin{tabular}{|l|l|}
\hline Semelhança & \multicolumn{1}{|c|}{ Verbalização das entrevistas } \\
\hline Metodologia e Aprendizado & $\begin{array}{l}\text { Suj. A [...] a metodologia utilizada é } \\
\text { muito melhor que no regular, e muito } \\
\text { valioso porque não interrompem a } \\
\text { sequência do conteúdo e tem a } \\
\text { possibilidade de acabar tudo estudar } \\
\text { melhor por que são só as três } \\
\text { disciplinas. } \\
\text { Suj. D [...] eu acho muito bom à } \\
\text { metodologia do SOME. Pois eles } \\
\text { trabalham o máximo dos conteúdos } \\
\text { possíveis em que trabalham na cidade } \\
\text { em um período muito curto de tempo. } \\
\text { Me permiti aprender mais, sendo que } \\
\text { dá para se dedicar mais as três } \\
\text { disciplinas. }\end{array}$ \\
\hline
\end{tabular}

\section{Fonte: Dados levantados pela pesquisa}

No que diz respeito à metodologia e aprendizado a pesquisa revelou que o currículo do Ensino Médio ofertado pelo SOME é estruturado com base num modelo de organização curricular centrado nas séries e nas disciplinas. Planejado para dar conta da oferta das disciplinas entre os circuitos que são realizados nas comunidades rurais, o currículo do Sistema Modular está programado por blocos de disciplinas. 
Neste caso, o trabalho docente tem sido realizado por um sistema de rodízio entre os professores e as turmas dentro dos circuitos, com o intento de suprir a distribuição das disciplinas e a oferta que está sendo programada para as comunidades atendidas com esta modalidade de ensino em Cametá.

Nossa pesquisa no SOME revelou ainda que muitos fatores contribuem para que os sujeitos do campo acreditem que o modelo de escola modular seja a referência de uma educação de qualidade para a zona rural, visto que consideram mais fácil assimilar os conteúdos por conta de estudarem apena três disciplinas por modulo.

Percebe-se, assim, na visão dos alunos o modelo de ensino por módulos tornou-se adequado, uma vez que os professores são deslocados de sua residência de origem para trabalharem nessas localidades e, ao final de quatro módulos, o aluno que não tem a opção de morar em centros urbanos pode concluir um ano de escolaridade de forma sucessiva, finalizando seus estudos na educação básica.

Entre as situações e os desafios pedagógicos enfrentados pelos educadores do Sistema Modular de Ensino, aparece à estruturação do currículo escolar definido aos moldes do currículo da escola urbana, levando os educadores a organizarem seus planos de aula e executarem o trabalho docente diante da limitação da carga horária e do cumprimento do conteúdo exigido pela disciplina, enfatizando a padronização curricular, a limitação de carga horária e a pouca disponibilidade de infraestrutura pedagógica. Com a definição do planejamento curricular e a organização dos circuitos, os professores do SOME são levados a trabalhar o currículo de forma limitada, ou até mesmo de forma parcial, e está centrada num modelo de aula com base na transmissão dos conteúdos curriculares. Consequentemente traçou-se uma política de educação para o Ensino Médio no campo baseada em um currículo fotográfico e comprimido aos moldes do currículo padrão escolar urbano.

Em vista dessa premissa, em geral os professores ficam limitados a desenvolver seus planejamentos de aula e acabam reduzindo suas práticas docentes em aulas expositivas e verbalizadas, contando em poucos casos com Datashow e outros recursos audiovisuais. Diante das limitações do trabalho docente, as aulas realizadas nos circuitos assumem a característica de uma didática chamada por Libâneo (2008) de "Triângulo Didático", na qual a prática docente está centrada na 
relação triangular entre disciplina, quadro negro e conteúdo. Para o autor, o "triângulo didático" tem assumido um padrão de referência na execução do trabalho pedagógico dentro das salas de aula, impactando negativamente na transmissão dos conteúdos e na construção das aprendizagens estudantis.

Identificamos essas características presente na organização da carga horária e nos conteúdos, onde a prática docente tem sido direcionada para a transmissão dos conteúdos do ensino médio voltados para o vestibular, enfatizando o conhecimento científico como padrão de referência para a aprendizagem com base na memorização dos conhecimentos. Nesse caso, compreendemos que o currículo escolar seriado no SOME tem impactado fortemente na organização curricular, na prática docente e na aprendizagem dos estudantes.

No âmbito metodológico, esse discurso se assenta no paradigma da adaptação curricular que estabelece padrões exteriores como universais para o processo de ensino-aprendizagem e provoca uma prática secundária de adequação aos conhecimentos locais. Convém ratificar que esse paradigma curricular para o ensino médio no campo apresenta e impõe um padrão de pensar, de agir, de sentir, de sonhar e de ser de acordo com os princípios e valores de uma racionalidade e sociedade capitalista e mercadológica, excluindo outros modos de representar o mundo e produzir a vida.

Podemos verificar durante a realização da pesquisa que o modelo de organização curricular é definido com base no desenvolvimento do módulo como um fator que orienta a oferta e a distribuição das disciplinas.

Entre as situações e os desafios pedagógicos enfrentados pelos educadores do Sistema de Organização Modular de Ensino, aparece a estruturação do currículo escolar definido aos moldes do currículo da escola da cidade, levando os educadores a organizarem seus planos de aula e executarem o trabalho docente diante da limitação da carga horária e do cumprimento do conteúdo exigido pela disciplina, como podemos verificar a evidência nas opiniões dos egressos do SOME, enfatizando a padronização curricular, a limitação de carga horária e a pouca disponibilidade de infraestrutura pedagógica. 
Em vista de cumprir seu papel, o professor organiza o fazer pedagógico, buscando orientações: da Equipe Gestora, conceitos de sua formação acadêmica, da proposta pedagógica da escola; conteúdos apontados pelas universidades, e principalmente quando existe, diagnósticos mapeando os paradigmas da comunidade escolar em questão. Todas essas informações e outras mais, próprias da profissão de professor, devem gerar reflexões acerca da prática. A concepção de educação, escola, planejamento, currículo, ensino, aprendizagem e avaliação devem permear a tomada de decisões no processo.

Neste sentido, Vieira (2004), aponta quatro características constitutivas da tarefa do professor: "ensinar a ensinar, que corresponde à capacidade do professor em organizar e dar coerência ao processo ensino-aprendizagem; ensinar a aprender, compete orientar e direcionar as atividades cognitivas do aluno a partir de movimento dialético do ensinar e do aprender, ou seja, em que possam socializar conhecimentos; ensinar a pesquisar, utiliza a pesquisa como instrumento de acesso, produção de conhecimento, significa utilizá-la no ensino, na aprendizagem e na avaliação, porque possibilita a investigação, constatação e a intervenção e, finalmente ensinar a avaliar, instrumento utilizado para diagnosticar a qualidade dos resultados".

Freire salienta a importância do diálogo na busca do conhecimento:

Os métodos da educação dialógica nos trazem à intimidade da sociedade, à razão de ser de cada objeto de estudo. Através do diálogo crítico sobre um texto ou um momento da sociedade, tentamos penetrá-lo, desvendá-lo, ver as razões pelas quais ele é como é, o contexto político em que se insere. Isto é para mim um ato de conhecimento e não uma mera transferência de conhecimento, ou mera técnica para aprender o alfabeto. $\mathrm{O}$ curso libertador "ilumina" a realidade no contexto do desenvolvimento do trabalho intelectual sério. (FREIRE, SHOR, 2003, p. 24-25).

É necessário compreender as questões fundamentais que se colocam no contexto da existência humana, assim como a capacidade de perceber as ligações entre as várias dimensões da realidade, devem fazer parte do currículo. Conhecer neste sentido é um ato dos sujeitos atuantes, que ao refletirem sobre o seu meio social, o entendem vislumbrando possibilidades de mudança. O modo de refletir sobre a realidade varia de época para época, de lugar para lugar. O conhecimento é, portanto, histórico, renovando-se constantemente, na medida em que não é algo acabado e definitivo. 


\section{CONSIDERAÇÕES FINAIS}

A realidade da escola nas regiões ribeirinhas no estado do Pará representa um grande desafio para os poderes públicos em nível federal, estadual e municipal. $O$ objetivo principal desta pesquisa voltou-se a expor e analisar as principais demandas escolares enfrentadas pelos sujeitos educacionais ribeirinhos, em especial pelos estudantes que buscam a efetivação de seus estudos por meio do Sistema de Organização Modular de Ensino (SOME/SEDUC/PA), a partir de um caso específico na Escola Municipal de Ensino Fundamental Prof. ${ }^{\text {a }}$ Raimunda Pontes, localizada na comunidade de Joroca Grande, município de Cametá/Pá.

As análises realizadas em relação à legalidade do ensino por meio de leis (LDB 9.394/96 e a Lei do SOME 7.806/2014) permitem compreender que existe uma disparidade entre aquilo que a lei propõe e a vivência prática do ensino na comunidade de Joroca Grande/Pá, principalmente quanto à questão da qualidade do ensino ofertado em escolas públicas municipais e estaduais (BRASIL, 1996). Quanto às problemáticas infra estruturais e pedagógicas do processo educativo observadas no caso selecionado, os depoimentos dos entrevistados demonstram percepções muito afinadas.

O SOME, como alternativa de escolarização para muitos jovens e adultos do interior do estado do Pará, é um sistema que precisa ser mais bem planejado pelos órgãos educacionais que lhe gerenciam. Nesta pesquisa não conseguimos obter os documentos referenciais de planejamento, execução e avaliação, ou seja, o SOME, ao completar mais de 35 anos de existência, ainda não possui um Projeto norteador para seus objetivos e finalidades. Causando um forte impacto nos trabalhos dos professores e alunos, que na maioria deixam de planejar e projetar propostas inovadoras e atualizadas para um ensino que articule as vivências dos alunos e seu contexto.

A realidade apresentada nos revela um grande desafio para que os objetivos do SOME sejam efetivados de acordo com a legislação vigente e que definem os parâmetros de qualidade do ensino público. Apresentando o quadro nada agradável em que se encontra a escola pesquisada, faz-se necessária uma verdadeira intervenção pedagógica e estrutural nas condições objetivas e subjetivas no contexto 
escolar do SOME. De certa maneira e de acordo com os dados até então apresentados, fica clara a necessidade de implantação de Políticas Focais para o SOME, já estabelecidas em documentos legais, visando atender com qualidade a população que necessita de escolarização na área rural.

Essa real situação em que se encontra o contexto educativo do SOME é muito complexa e se configura com um verdadeiro desafio para todos os segmentos educativos (direção, professores, alunos e coordenação) da referida escola e isso nos leva a indicar algumas possibilidades de intervenção, como meios de solucionar as problemáticas elucidadas referentes ao SOME. A nosso ver são medidas simples, que podem ser desenvolvidas na coletividade escolar considerando a escola sede e a escola que recebe o SOME e que exprimem as expectativas de todos os envolvidos nesse contexto: Construção coletiva de um Projeto Político Pedagógico (PPP) em que todos os segmentos educacionais possam participar, encontros coletivos para ouvir os sujeitos e suas reais ansiedades e objetivos para a melhoria do ensino, ressignificar o trabalho pedagógico realizado na escola, isto é, com a construção de projetos de intervenção que contemplem a vivência dos alunos, formação permanente de professores do SOME e a efetivação de semana pedagógica no início de cada semestre, efetivação de serviço técnico pedagógico como ferramenta de auxílio no processo de um ensino de qualidade, ação coletiva entre as parcerias para a garantia de uma educação de qualidade no contexto do SOME e avaliação permanente das ações realizadas no SOME para a efetivação de um processo de ensino aprendizagem efetivo e atualizado de acordo com a realidade dos alunos.

É necessário que os nossos dirigentes (federal, estadual e municipal) implementem ações voltadas à essas questões, bem como tenham a capacidade de compreensão dos graves problemas enfrentados por professores, alunos, diretores e pessoal de apoio das escolas localizadas no campo amazônico. Por outro lado, as comunidades locais precisam se organizar e promover movimentos no sentido de cobrar dos poderes constituídos que seja efetivamente oferecida uma educação de pública, gratuita e de qualidade para todos os brasileiros, inclusive e principalmente, para todos aqueles e aquelas afastados dos centros urbanos.

Identificar as dificuldades e prosperidade no ensino modular, exige uma reformulação política curricular e da prática docente que viabilize com mais eficiência 
a materialização de uma educação que tenha como meta a formação para o trabalho, a vida e o exercício da cidadania.

As referências bibliográficas vêm apontando a importância dos movimentos sociais como articuladores de experiências que podem contribuir muito com a melhoria do ensino modular bem como a qualidade de vida dos jovens que moram e trabalham no campo.

A presente pesquisa tem a finalidade de elaborar um quadro ampliado da política de ensino médio modular no Estado do Pará, especificamente no município de Cametá, que apresenta um alto índice de atendimento pelo Sistema Modular de Ensino nas regiões ribeirinhas.

Portanto, é necessário que os Governos do Estado brasileiro projetem e efetivem políticas públicas educacionais de garantia de construções de escolas, exclusivamente para o atendimento do ensino fundamental e médio no campo, com modernos equipamentos, biblioteca com variados livros didáticos e investimento na formação continuada no nível de pós-graduação específico em educação do campo para os professores deste sistema para que possam promover uma educação do campo de qualidade social, fundamentada principalmente no valor cultural do cotidiano dos sujeitos campesinos, criando dessa forma, condições dignas de aprendizagem para os educandos e espaço escolar adequado para o desenvolvimento do trabalho docente.

\section{REFERÊNCIAS}

BRASIL. Ministério da Educação. Parecer CNE/CEB № 15/98. Diretrizes Curriculares. Nacionais para o Ensino Médio. In: NUNES, Clarice. Ensino Médio. RJ: DP\&A, 2002a. (Diretrizes Curriculares Nacionais para o Ensino Médio).

dezembro $1996 . \quad$ Disponível <http://www.planalto.gov.br/ccivil_03/Leis/L9394.htm>. Acesso em: 18 outubro 2020.

BARDIN, Laurence. Análise do conteúdo. São Paulo: Edições 70, 2016.

CASTRO, Elisa Guaraná de. Juventude rural: "apenas uma palavra" ou "mais que uma palavra". XXIX Encontro Anual da ANPOCS. 2005a. 
CORRÊA, Paulo Sérgio de Almeida; BARRETO, Edna Abreu. O ensino médio no estado do Pará segundo as estatísticas oficiais: os impasses das políticas públicas educacionais e os desafios para o século XXI. Paper do NAEA, Belém, n. 122, ago. 1999.

CURY, Carlos Roberto Jamil. Livro didático como assistência ao estudante. Revista Diálogo Educacional, Curitiba, v. 9, n. 26, p. 119-130, jan./abr. 2009.

DEMO, Pedro. Metodologia cientifica em ciências sociais. 3aㅡ Ed. São Paulo, Atlas, 1995.

FRIGOTTO, Gaudêncio; CIAVATTA, Maria. Perspectivas Sociais e Políticas de Formação de Nível Médio: Avanços e Entraves nas suas modalidades. Educação e Sociedade, Campinas, v. 32, n. 116, p. 619-638, jul./set. 2011. Disponível em: <http://www.scielo.br/ pdf/es/v32n116/a02v32n116.pdf>. Acesso em: 14 novembro. 2020.

FRIGOTTO, Gaudêncio; CIAVATTA, Maria; RAMOS, Marise (Org.). Ensino Médio Integrado: Concepções e contradições. São Paulo: Cortez; Rio de Janeiro: Escola Politécnica de Saúde Joaquim Venâncio, 2005.

GIL, Antônio Carlos. Como elaborar projetos de pesquisa. 4. ed. São Paulo: Atlas, 2008.

GONÇALVES, Dalvina de França. Aprendizagem na leitura da escrita em sala de aula. Mari, novembro de 2006.

LOPES, Harry Vieira. A prática do português no 1 grau: objetivos, conteúdos, metodologia e avaliação. In: Murrie, Zuleika de Felice (org.) Universos da palavra. São Paulo: Iglu, 1995, p. 95-167.

MANZINI, Eduardo José. Entrevista semiestruturada: Analise de Objetivos e de Roteiros. Depto de educação especial do programa de Pós-Graduação em Educação, Universidade Estadual São Paulo (UNESP), Marilia, SP. 2004. Disponível em: [http://www.sepq.org.br/llsipeq/anais/pdf/gt3/04.pdf]; acesso em 16.02.2021

MINAYO, M.C. de S. O desafio do conhecimento: pesquisa qualitativa em saúde. São Paulo- Rio de Janeiro, HUCITEC-ABRASCO, 1992.

PARÁ. Caderno de elementos para uma política educacional democrática e de qualidade para todos. Belém: SEDUC, 2008a.

PARÁ. Fundação Educacional do Estado do Pará. Sistema de Organização Modular de Ensino Superior: interiorização. Belém, 1980.

PARÁ. Governo do Estado. Projeto Alvorada. Belém, 2006. 